\title{
Comparative evaluation of micro-leakage of two newer glass ionomer cements in primary molars immersed in three beverages: in vitro study
}

\author{
P Balgi, F Katge, D Pradhan, S Shetty, B Rusawat, S Pol
}

\begin{abstract}
Introduction The dietary habits of children expose the oral cavity to challenging environments. A durable interface between the restorative material and tooth surface is essential to ensure marginal integrity thereby contributing to the longevity of restoration.
\end{abstract}

Objectives The objective of this study was to compare the micro-leakage of two newer glass ionomer cements (SDI Riva Self Cure GIC and GC Fuji IX GP EXTRA) in primary molars immersed in sugarcane juice, chocolate milk and mango drink.

Methods The study included 60 extracted non carious upper and lower primary molars. The buccal and lingual surfaces were restored with SDI Riva Self Cure GIC and GC Fuji IX GP EXTRA respectively. The sample was divided into three groups (chocolate milk, mango drink, sugarcane juice). Each group $(\mathrm{n}=18)$ was further subdivided into three subgroups based on the immersion regime. Six teeth were kept as control. The teeth were immersed in Rhodamine B dye. Following this, micro-leakage was determined under $40 \mathrm{x}$ stereomicroscope.

Results Both the materials showed microleakage when immersed in the three beverages. When specimen under each group were compared, the microleakage score increased with an increase in immersion frequency. This was not statistically significant. The microleakage values for both the materials immersed in the three beverages were not significant.

Conclusion Both the materials used in this study can be conveniently used in restoration of primary molars.

Ceylon Medical Journal 2017; 62:184-188

DOI: http://doi.org/10.4038/cmj.v62i3.8522

Department of Paedodontics and Preventive Dentistry, Terna Dental College, India.

\section{Introduction}

Dietary patterns of children have seen a drastic change in the past few decades. The influence that these dietary alterations have on the oral health cannot be overlooked. From a decrease in milk consumption to an increase in consumption of soft drinks and non-citrus juices, the oral cavity is exposed to challenging environments. It is known that recurrent exposure of the oral cavity to acidic beverages results in loss of dental hard tissues [1]. Also, the restorative materials are subject to change after exposure to beverages in the oral cavity. Wilson and Kent introduced glass ionomer cement in the year 1971 [2]. It has been the mainstay for restorative dentistry in children. The material has been used as liner, base or for restorative purposes depending on the need [3].

The materials compared in this study were Southern Dental Industries (SDI) Riva Self Cure glass ionomer cement (GIC) and General Chemicals (GC) Fuji IX GP EXTRA. SDI Riva Self Cure utilizes SDI's proprietary ion glass filler. GC Fuji IX GP EXTRA contains glass fillers. The addition of these fillers reinforces the mechanical properties. These are the claims made by the manufacturers of their respective companies. Recent advances in the glass ionomer cements by incorporation of bioactive ions and nanofillers have improved the physical properties of the restorative material. It also enhances fluoride release and bioactivity of the material [4].

Correspondence: FK, E-mail: <pedotdc@gmail.com>. Received 21 March 2017 and revised version accepted 24 July 2017. 
One of the factors critical for the success of any restorative material is its marginal adaptation. A durable interface between the restorative material and tooth surface is essential to ensure marginal integrity thereby contributing to the longevity of restoration. Clinically, poor marginal adaptation is discernible as stained margins around restorations, post-operative sensitivity and secondary caries [5].

The objective of this study was to evaluate and compare the micro-leakage of two newer glass ionomer cements (SDI Riva Self Cure GIC and GC Fuji IX GP EXTRA) in primary molars immersed in sugarcane juice, chocolate milk and mango drink.

\section{Methods}

The study included 60 extracted non carious, upper and lower primary molars. Class V cavities were prepared on the buccal and lingual surfaces of these teeth, $1 \mathrm{~mm}$ above the cemento-enamel junction (CEJ). The cavity preparation was standardized using a William's graduated probe. The dimensions of the cavity were decided to be $3 \mathrm{~mm}$ mesio-distally, $2 \mathrm{~mm}$ occluso-cervically and $2 \mathrm{~mm}$ in depth. The manipulation of both restorative materials was done while strictly adhering to the manufacturer's guidelines. The buccal and lingual/palatal cavity were restored with SDI Riva Self Cure GIC and GC Fuji IX GP EXTRA respectively.

Following restoration, the sample was immersed in saline for 7 days. During this period, the teeth were thermocycled 200 times in distilled water ranging between $5^{\circ} \mathrm{C}$ and $55^{\circ} \mathrm{C}$. The temperature was checked with a thermometer. The dwell time was 1 minute and transit time was 10 seconds. The thermocycling regime was evenly distributed over a period of 24 hours. The teeth were divided into three groups as group I- chocolate milk (18 teeth), group II- mango drink (18 teeth) and group III- sugarcane juice (18 teeth). The remaining six teeth were kept as controls.

Each group was subdivided into three subgroups based on the immersion regimes. The low, medium and high immersion regime corresponded to 1, 5 and 10 immersions respectively. Each immersion lasted for 5 minutes.

This was followed by sealing of the apices of teeth with sticky wax to prevent dye penetration through the apices. The teeth were then immersed in Rhodamine B dye for 24 hours. The sample teeth were gently washed under tap water to get rid of the excess dye. Each tooth was invested in autopolymerising resin below the CEJ. The tooth was then sectioned bucco-lingually into two halves with a low speed, water cooled diamond disc mounted on a mandrel. The test samples obtained were examined under $40 \mathrm{x}$ stereomicroscope to evaluate the micro-leakage. The dye penetration that ensued as a result of micro-leakage was graded according to the criteria given by Staninec and Holtz [6].

Score 0- No dye penetration, Score 1- Dye penetration along occlusal wall but less than half way to axial wall, Score 2- Dye penetration along occlusal wall but more than half way to the axial wall, Score 3- Dye penetration along occlusal wall upto and along axial wall.

The samples were cross verified by an independent examiner to eliminate bias. The statistical analysis was done using SPSS (version 16.0) software. ANOVA was used to compare means. The results were considered statistically significant at $\mathrm{p} \leq 0.05$.

Ethical clearance was obtained from the institutional review board of Terna Dental College, Navi Mumbai (TDC/IRB-EC/120/2016). The extracted teeth used in the study were obtained from various sources. Consent from parent or guardian for individual teeth extraction was taken by the dentist performing the procedure.

\section{Results}

The descriptive data for SDI Riva Self Cure GIC and GC Fuji IX GP EXTRA are given in Table 1 and Table 2 respectively. The minimum microleakage score was 0 and maximum score was 2 for both the materials.

When specimens within the groups were compared (intragroup comparison) for each material, micro-leakage scores increased with an increase in the frequency of immersion. However, this was not statistically significant. ANOVA test did not show a statistically significant difference in the intergroup comparisons for both materials $(\mathrm{p}>0.05)$. (Supplementary Tables 3 and 4).

\section{Discussion}

The result of our study showed that the micro-leakage scores increased with an increase in immersion frequencies for both the materials, but this was not statistically significant. Micro-leakage values for both the materials immersed in the three beverages employing different regimes were not significantly different.

Glass ionomer cement is indicated for restoration of primary molars because it adheres chemically to the tooth and has fluoride releasing capability [3]. Previous studies have concluded that 
conventional glass ionomer cement is inappropriate for use in primary molars owing to its low physical properties and poor long-term performance $[3,7]$. However evolution in the glass ionomer cement seems to favour it currently for restoration of primary molars. This has been attributed to better handling characteristics and higher strengths exhibited by the newer materials.

The restorative materials used in this study were the SDI Riva Self Cure GIC and GC Fuji IX GP EXTRA. SDI Riva Self Cure utilizes SDI's proprietary ionglass filler. The manufacturers claim that this makes the material radiopaque, high ion and substantially higher fluoride releasing to assist with mineralization of natural dentition. The other material used was the GC Fuji IX GP EXTRA which contains glass fillers, SmartGlass. Due to the presence of these glass fillers, the material elicits higher translucency, compressive strength and fluoride release.

Class $\mathrm{V}$ cavities of maxillary and mandibular first and second primary molars were restored with these materials. The dye used was Rhodamine B. Studies performed previously have used $1 \%$ methylene blue, acridine dye, silver nitrate $[5,8,9]$. As recommended by the manufacturer of SDI Riva Self Cure GIC, the cavity on the buccal surface was conditioned with $37 \%$ phosphoric acid for 10 seconds. However, studies in the past demonstrated no effect on the bond strength and micro-leakage of self-cured GICs regardless of the use of cavity conditioner $[10,11]$. Aerated drinks and citrus beverages have been used to determine its effects on micro-leakage [12-14]. These studies showed that the acidic beverages had an erosive potential and affected the marginal integrity of the restorative material $[12,13]$. We chose chocolate milk, mango drink, sugarcane juice to know if nonaerated drinks had an effect on micro-leakage.

The teeth following restoration were stored at room temperature. The thermo-cycling protocol simulated the oral environment. It followed the one that was used in previous studies dealing with microleakage of restorative materials [8,9;12-14]. Bullard et al stated that the thermo-cycling process may be responsible for stress build up within the material thereby increasing leakage [15]. Studies performed previously had immersion regimes ranging from 15 minutes to 72 hours $[12,13]$. This may not be similar to the normal food consumption pattern. Also, the impact of frequency of immersion is not precisely portrayed in these studies. Hence, a more representational consumption pattern described by Maupome et al. was considered in our study [16].

Diwanji et al compared Fuji IX, Fuji II LC and Ketac N 100. Their study showed maximum micro-leakage with Fuji I while Ketac N 100 showed minimum micro-leakage. However, there was no immersion medium used in their study [5]. In our study, GC Fuji IX GP EXTRA showed higher microleakage scores when compared to SDI Riva Self Cure GIC when immersed in mango drink.

A study performed by Sabdi et al. assessed micro-leakage of Filtek Z250, Fuji IX, Fuji II LC and Silver fill amalgam after immersing them in lime juice. However, no immersion regimen was employed and Fuji IX showed highest micro-leakage scores amongst the test specimens [8]. There is very limited evidence available on micro-leakage of newer glass ionomer cements in primary molars following an immersion sequence in different beverages.

The beverages used in this study were nonaerated. Osborn, Noriskin, and Staz demonstrated that certain substances in sugarcane juice reduced the rate of solubility of whole teeth incubated with saliva, without altering acid production [17]. Other authors substantiated this finding by confirming the presence of inorganic phosphate which is supposed to be actively involved in reducing the solubility of enamel [18-21]. The chocolate milk in our study was malt based and fortified with various minerals and vitamins. Another beverage used was a popular mango drink consumed by children. Lueangpiansamut et al, in their descriptive study showed that malt based beverages and fruit drinks carry a high risk of tooth decay [22]. This elucidates that improper dietary habits will hasten the development of secondary caries in a child whose teeth are restored with materials demonstrating poor marginal integrity.

In our opinion, both materials used in this study can be conveniently used in restoration of primary molars. It is important to establish appropriate dietary habits in children along with effective dental treatment. The restorative materials in the oral cavity are exposed to a dynamic environment. Because the current study was in vitro in nature, factors like saliva and other dietary habits were not accounted for. Further studies with a larger sample size and probably in vivo studies are recommended to corroborate these findings.

\section{Conclusion}

The materials used in the study exhibited micro-leakage after immersion in three different beverages. The extent of micro-leakage increased with an increase in immersion frequencies for both the materials. The difference were not statistically significant. 


\section{Acknowledgement}

We would like to thank the Department of Oral Pathology, Terna Dental College for their support with stereomicroscopic examination. We would also like to thank the Department of Public Health Dentistry, Terna Dental College for their assistance with the statistical analysis.

\section{Conflicts of interest}

There are no conflicts of interests.

\section{References}

1. Dye BA, Shenkin JD, Ogden CL, Marshall TA, Levy SM, Kanellis MJ. The relationship between healthful eating practices and dental caries in children aged 2-5 years in the United States, 1988-1994. J Am Dent Assoc 2004; 135: 55-66.

2. Wilson $\mathrm{AD}$ and Kent BE. A new translucent cement for dentistry. The glass ionomer cement. Br Dent J 1972; 132:133-5.

3. Berg JH. The continuum of restorative materials in pediatric dentistry- a review for the clinician. Pediatr Dent 1998; 20: 93-100.

4. Najeeb et al. Modifications of Glass Ionomer Cements: Nano Sized Fillers and Bioactive Nanoceramics. Int J Mol Sci 2016; 17: 1134-51.

5. Diwanji A, Dhar V, Arora R, Madhusudan A, Rathore AS. Comparative evaluation of microleakage of three restorative glass ionomer cements: An in vitro study. J Nat Sc Biol Med 2014; 5: 373-7.

6. Staninec M, Holt M. Bonding of amalgam to the tooth structure: tensile adhesion and microleakage tests. J Prosthet Dent 1998; 59: 397-402.

7. Cho SY, Cheng AC. A review of Glass Ionomer Restorations in the Primary Dentition. J Can Dent Assoc 1999; 65: 491-5.

8. Sabdi S, Bakar WZ, Husein A. Assessment of microleakage of few restorative materials after erosion by acidic solution. Arch Orofac Sci 2011; 6: 66-72.

9. Castro AC, Feigal RF. Microleakage of a new improved glass ionomer restorative material in primary and permanent teeth. Pediatr Dent 2002; 24: 23-8.

10. Inoue S, Abe Y, Yoshida Y, De Munck J, Sano $\mathrm{H}$, Suzuki $\mathrm{K}$, et al. Effect of conditioner on bond strength of glass-ionomer adhesive to dentin/enamel with and without smear layer interposition. Oper Dent 2004; 29: 685-92.
11. Rao KS, Reddy TP, Yugandhar G, Kumar BS, Reddy SN, Babu DA. Comparison of shear bond strength of resin reinforced chemical cure glass ionomer, conventional chemical cure glass ionomer and chemical cure composite resin in direct bonding systems: an in vitro study. $J$ Contemp Dent Pract 2013; 14: 21-5.

12. Katge F, Shitoot A, Pammi T, Mithiborwala S. Evaluation of Microleakage of Nanoionomer and Nanocomposite Restorations, immersed in Fruit Drink, Fresh Fruit Juice and Soft Drink An in vitro Study. J Clin Pediar Dent 2016; 40: 129-35.

13. Maganur PC, Prabhakar AR, Sugandhan S, Namineni S. Evaluation of microleakage of RMGIC and Flowable Composite Immersed in Soft Drink and Fresh Fruit Juice: An in vitro study. Int J Clin Pediatr Dent 2010; 3: 153-61.

14. Narsimha VV. Effect of Cola on Surface Microhardness and Marginal Integrity of Resin Modified Glass Ionomer and Compomer Restoration - An in vitro Study. People's J Scientific Res 2011; 4: 34-40.

15. Bullard RH, Leinfelder KF, Russell CM. Effect of coefficient of thermal expansion on microleakage. J Am Dent Assoc 1988; 116:8714.

16. Maupome G, Diez-de-Bonvilla J, TorresVillasenor G, Andrade-delgado LC, Castano VM. In vitro quantitative assessment of enamel microhardness after exposure to eroding immersion in a cola drink. Caries Res 1998; 32: 148-53.

17. Osborn T.W.B, Noriskin J.N, Staz. J. A comparison of crude and refined sugar and cereals in their ability to produce in vitro decalcification of teeth. J Dent Res 1937; 16: 165-71.

18. Jenkins G.N, Forster M.G, Speirs R.L. And Kleinberg, I.The influence of the refinement of carbohydrates on their cariogenicity. In vitro experiments on white and brown flour. Brit Dent $J$ 1959; 106: 195-208.

19. Andlaw R.J. The relationship between acid production and enamel decalcification in salivary fermentations of carbohydrate foodstuffs. I Dent Res 1960; 39: 1200-9.

20. Grenby T.H. Wheat bran factors in decalcification tests. Arch Oral Biol 1967; 12: 523-9.

21. Grenby TH. Phytates in decalcification tests in vitro. Arch Oral Biol 1967; 12: 531-7.

22. Lueangpiansamut J, Chatrchaiwiwatana, $S$ Muktabhant B, Warangkana Inthalohit W. Relationship Between Dental Caries Status, Nutritional Status, Snack Foods, and SugarSweetened Beverages Consumption Among Primary Schoolchildren Grade 4-6 in Nongbua Khamsaen School, Na Klang District, Nongbua 
Table 1. Microleakage pattern of SDI Riva Self Cure GIC following different immersion frequencies in chocolate milk, mango drink, sugarcane juice and control group

\begin{tabular}{|c|c|c|c|c|c|}
\hline $\begin{array}{l}\text { SDI Riva } \text { Self } \\
\text { cure GIC }\end{array}$ & Number & Minimum & Maximum & Mean & Std. Deviation \\
\hline IA & 6 & 0 & 1 & .17 & .408 \\
\hline IB & 6 & 0 & 1 & .33 & .516 \\
\hline IC & 6 & 0 & 1 & .67 & .516 \\
\hline IIA & 6 & 0 & 1 & .33 & .516 \\
\hline IIB & 6 & 0 & 1 & .33 & .516 \\
\hline IIC & 6 & 0 & 2 & 1.00 & .632 \\
\hline IIIA & 6 & 0 & 1 & .33 & .516 \\
\hline IIIB & 6 & 0 & 1 & .50 & .548 \\
\hline IIIC & 6 & 0 & 2 & .83 & .753 \\
\hline IV (Control) & 6 & 0 & 1 & .17 & .408 \\
\hline
\end{tabular}

Table 2. Microleakage pattern of GC Fuji IX GP EXTRA following different immersion frequencies in chocolate milk, mango drink, sugarcane juice and control group

\begin{tabular}{|c|c|c|c|c|c|}
\hline $\begin{array}{l}\text { GC Fuji IX GP } \\
\text { Extra }\end{array}$ & $\mathbf{N}$ & Minimum & Maximum & Mean & Std. Deviation \\
\hline IA & 6 & 0 & 1 & .33 & .516 \\
\hline IB & 6 & 0 & 1 & .50 & .548 \\
\hline $\mathrm{IC}$ & 6 & 0 & 2 & .83 & .753 \\
\hline IIA & 6 & 0 & 1 & .17 & .408 \\
\hline IIB & 6 & 0 & 1 & .50 & .548 \\
\hline IIC & 6 & 0 & 2 & .83 & .753 \\
\hline IIIA & 6 & 0 & 1 & .33 & .516 \\
\hline IIIB & 6 & 0 & 2 & .83 & .753 \\
\hline IIIC & 6 & 0 & 2 & 1.17 & .753 \\
\hline IV (Control) & 6 & 0 & 1 & .33 & .516 \\
\hline
\end{tabular}

This is an open-access article distributed under the terms of the Creative Commons Attribution License, which permits unrestricted use, distribution, and reproduction in any medium, provided the original author and source are credited. 